\title{
Acute Acoustic Trauma - Its Features And Management
}

\section{Oberfeldarzt Dr Med M Kersebaum}

\author{
Maj JDC Bennett \\ FRCS, MRCPCH, RAMC*
}

\author{
BwZK Koblenz Ruebenacherstr 170, 56064 Koblenz, Germany
}

SUMMARY: The features and mechanism of Acute Acoustic Trauma (AAT) together with available treatments are discussed and the current guidelines in use by the Bundeswehr are also presented.

\section{Introduction}

In most industrialised nations, deafness caused by exposure to noise is the most common occupational disease (in Germany it is Berufskrankheit/occupational disease 2301). In addition to hearing loss, there are also deleterious effects on the cardiovascular (blood pressure and atherosclerosis) and gastrointestinal (ulcers) systems. The hazards of prolonged exposure to high noise levels are well known and have been described elsewhere (1). Effective safety levels have been formulated and protective devices are not only provided but their use is practised and familiar. AAT is a further hazard which, owing to its more difficult measurement, is not well known, yet the consequences are just as serious, if not more so.

AAT may be divided into two main groups: Impulse and Explosion, depending on the sound pressure level and the duration of the noise pressure peaks. The phenomenon was first investigated by Haberman who, in 1890, demonstrated defects in the organ of Corti of the basal turn of the cochlea following exposure. He undertook post mortem examinations of large groups of workers such as boilermakers and weavers (2). Of course, it has been known since biblical times that prolonged exposure to loud noise can lead to deafness, and this was dramatically shown by the experience in 1872 of Admiral Rodney who lost his sense of hearing for nearly two weeks after repeated firing of broadsides from his flagship (3). Animal experimentation followed, with Siebenmann in 1915 studying the effect on cochleas after deliberate exposure to explosive damage (4). With the development of audiometers in the nineteen-thirties it became possible to more accurately correlate hearing loss with noise damage, Bunch publishing in 1937 the first audiometric data demonstrating the typical high frequency loss (5).

Increasing power of military weapons was being seen even before the Second World War as a threat to hearing. A new anti-tank weapon introduced into the Wehrmacht 1934-36 had a particularly high projectile velocity with a consequent high pulsed noise. Its effects were studied by Pfander and as early as 1935 he was able to show that more than half the gunners assigned to it suffered temporary (and 10\% permanent) hearing loss after firing 30-100 rounds without ear protection (6). There is considerable biological variation in sensitivity between individuals, something that was dramatically proved in experiments performed on medical students: rifles were fired a few centimetres from their ear (causing in some cases permanent hearing loss!) (7). A single acoustic trauma can be the cause of lasting inner ear hearing loss and tinnitus. The physiological bases of this phenomenon have still not been clarified at molecular level.

We should now distinguish between chronic exposure to loud noise and AAT. In AAT the extent of damage depends on the level of the peak pressure, the steepness of pressure increase and the length of its duration (8). Such hearing loss following exposure to extreme noise over a short period is 음 termed an "acoustic incident" and has the following criteria, which were established some time ago but which are still valid (9):

- hearing disruption must have arisen within a short tim during a noise explosion

the noise must be of sufficient energy to cause disruption of the inner ear

the hearing loss must have a trough or flat trace on put tone audiometry with positive recruitment

there must be no vestibular dizziness

the deafness is always accompanied by subjective ear noises (tinnitus) and is usually irreversible.

Impulse trauma follows exceedingly loud intensities $(130-160 \mathrm{~dB}$ ) over a very short duration (a few milliseconds) - it can be caused by children's toys (10). In this it should be distinguished from prolonged noise exposure, the safe limits of which are $90 \mathrm{~dB}$ over an average working week. Damage is worst at the end of the first or beginning of the second spiral canal of the cochlea. Energy localised here by the travelling wave passing down the cochlea causes destruction of the outer hair cells of the organ of Corti. Rupture of the eardrum is rare and the middle ear is usually not involved.

In contrast, explosion trauma is often associated with rupture of the eardrum and there is usually a combined $\mathrm{O}$ conductive and sensorineural hearing loss. This is because it is associated with higher energy levels: the pressure peak is over $190 \mathrm{~dB}$ (c.f. impulse trauma $150-180 \mathrm{~dB}$ ) and of a longer duration than the $2-3 \mathrm{~ms}$ found in impulse trauma. This sort of insult is associated with high calibre weapons. O The nature of the insult can influence the effect. $\omega$ Hammernik has shown that pulses with a high frequency? 
spectrum can be more damaging than low frequency, even though the maximum sound pressure is the same (11).

\section{How Is Damage Caused? \\ Perilymph Fistula}

In AAT this is caused by a rupture of the round window membrane of the cochlea. There is a complete hearing loss across all the frequencies.

\section{Primary Damage}

Pulsed noise can cause tears in the basilar membrane. This results in an alteration in biochemical homeostasis affecting the action of the actin and myosin of the outer hair cells. Their motility fails, thus compromising the tuning ability of that portion of the cochlea.

More subtle than such dramatic tears are the effects on the stereocilia of the hair cells. Robertson exposed guinea pigs to $106 \mathrm{~dB}$ for an hour and observed collapse and fusion of stereocilia of the innermost row of outer hair cells (12). It was later shown that under conditions of pulsed sound of $155 \mathrm{~dB}$ the same could occur after an exposure of only $1 \mathrm{~ms}$. With continuing noise damage the stereocilia degenerate, but it is possible that some may revert to normal and it is on this basis that most treatment modalities are founded.

\section{Secondary Damage}

Local secondary damage arises from the accumulation of metabolic end products such as lactate from the breakdown of the outer hair cells. This alters the repolarising ability of those outer hair cells which remain (13).

It has been speculated that cytoskeletal proteins play a role in determining the susceptibility of the individual to AAT - it is well-known that inner ear damage following AAT does not always follow a strict dose-effect ratio (14).

\section{Predicting The Vulnerable Inner Ear}

\section{The role of high frequency loss as a predictor}

It has been found that before there is a measurable loss in the frequencies normally tested by pure tone audiometry (highest $8 \mathrm{KHz}$ ) that there is a fall off in the extended high tone range (i.e. up to $20 \mathrm{KHz}$ ). The difficulty in using this as a practicable means of screening is that usually the prior exposure to trauma and hearing losses are not known.

\section{Recovery time as a prognostic indicator.}

This is the duration of any temporary deafness (or "threshold shift") and is thus the time taken for the hearing level to return to normal (assuming it does) following acoustic trauma. Clearly this is not a very practicable test!

\section{Tinnitus}

Tinnitus which persists has been found to be an unfavourable prognostic indicator and points to persistent disruption of the cochlear micromechanism (15).

\section{The Basis of Treatment}

Non mammalian hair cells can regenerate after acoustic trauma provided that the function of the supporting cells 8 remains, but this has not been shown in mammalian outero hair cells (16). The basis of treatment is that oxygenation of the delicate hair cells of the organ of Corti which ares? damaged during AAT must be maintained. The cochlea is particularly sensitive owing to its arterial supply: the labyrinthine artery splits into the vestibular artery ande cochlear artery - which are both end-arteries.

Consequently, rheological factors must be optimised to ensure adequate oxygenation; these consist of:

- ensuring the haematocrit is less than $40 \%$

- ensuring a low plasma viscosity

- avoiding aggregation of blood cells

- ensuring adequate oxygenation of blood

- ensuring adequate blood flow.

These are thought to minimise secondary damage and allow any reparative (if not regenerative) processes to $\vec{A}$ proceed. There are many clinical studies which support the use of therapeutic methods of improving the blood/oxygenw supply to the cochlea, and, in the German and Frencheo armies, such treatment is obligatory following acuteo acoustic trauma. Nevertheless, research into efficacy uis hampered by the following:

- variability of exposure to noise (both continuous impulse)

- delay in implementation of treatment

- ignorance of pre-exposure deafness

- difficulty in differentiating spontaneous recovery fros that attributable to treatment.

\section{Hyperbaric Oxygen Therapy}

In a Bundeswehr study performed in 1985, Pilgramm and Schumann studied the effect of hyperbaric oxyger? therapy on acute acoustic trauma. They studied $122 \overline{0}$ soldiers, excluding those who had an early spontaneous remission (17). The patients accepted were divided into four treatment groups and results showed that hyperbaric oxygen was superior to infusion therapy withe. Betahistidine or treatment with bloodflow-stimulating medications.

\section{Infusion Therapy}

Following on from this work, at the same centro (Bundeswehrkrankenhaus Ulm), in a study undertaken by Korkmaz, Trental (pentoxifylline) was compared witl' Novocain (procaine hydrochloride), each as an infusion under hospital conditions (unpublished MD thesis, 1997)응 Novocain led to a statistically significant more rapid and complete restoration of hearing and resolution of tinnituso It was confirmed in both treatment groups that the leas optimistic outlook regarding both hearing loss and tinnitus comes from the greater impulse energy of explosior 5 trauma. Nevertheless, significantly better results can be obtained with Novocain than hyperbaric oxygen, which iso 
no longer used as a treatment for this condition by the Bundeswehr.

Current guidelines in use by the Bundeswehr are:

Admission to hospital and initiation of treatment should be within 72 hours of the damage being sustained.

Treatment can be stopped when the audiogram has returned to a steady state without tinnitus for at least two days.

Noise avoidance should be maintained for three months. Infusion regimen using Rheohes (hydroxy ethyl starch):

Days 1 and 2 Rheohes 250mg Solu-Decortin $\mathrm{H}$

Days 3 and 4 " 200mg "

Days 5 and 6 " " $150 \mathrm{mg}$

Days 7 and 8 “ “

Days 9 and $10 \quad$ “ $50 \mathrm{mg}$

In addition to the above, $3 \times 2$ Tabl. Dusodril retard (Naftidrofuryl) and $3 \times 1$ Tabl Neurotrat $S$ forte (Thymine and Pyridoxine) are given daily and continued for a further ten days, during which a reducing dose of prednisolone beginning with $40 \mathrm{mg}$ is started.

The above is in place for the Bundeswehr, but it should be noted in these days of multi-national operations that the German military hospital near Sarajevo is responsible for the ENT management of all NATO soldiers in the former Yugoslavia.

\section{Conclusion}

The acute onset of hearing loss following exposure to acute noise trauma should be treated as a medical emergency. In addition to sensorineural deafness, damage to the ear drum and conducting mechanism may occur following very loud noise (explosions). Prompt (within 72 hours) assessment by a specialist followed by management directed at improving the blood flow to the inner ear have been shown to be efficacious. This is the standard of care for the German and French armies and is the treatment given to the multi-national forces in Bosnia.

\section{REFERENCES}

1. BenNetT JDC. Downgraded Through My Hearing, Doctor? British Army Review 1993; 105: 32-35.

2. HABERMANN J, Uber die Schwerhörigkeit der Kesselschmiede. Arch Ohrenheilk 1890; 30: 1-25.

3. MAWsON SR. Diseases of the Ear. 3rd ed. London: Butterworth, 1976: 166.

4. SiebenmanN F. Akustisches Trauma und persönlicher
Schutz gegen professionelle Schwerhörigkeit. Korresp-Bl Schweiz Ärz 1915; 45: 385-389.

5. Bunch CC. Nerve Deafness of Known Pathology or Etiology; Diagnosis of Occupational or Traumatic Deafness; Historical and Audiometric Study. Laryngoscope 1937; 47: 615-691.

6. PFANDER F. Beiträge zur Schwerhörigkeit durch Waffenlärm. Münchn Med Wchsr 1937; 5: 184-185.

7. REID G. Further observations on temporary deafness following exposure to gunfire. J Laryngol Otol 1946; 60: 609-633.

8. PFander F. Änderung des Spitzendrucks und der Frequenz des Impulsschalls für das akustische Trauma of des Ohres. Laryngol Rhinol Otol (Stuttg) 1981; 60: 517-519.

9. BoEnninghaus HG. Ungewöhnliche Form der $\vec{\omega}$ Hörstörung nach Lärmeinwirkung und Fehlbelastung 疋 der Wirbelsäule. Z Laryngol Rhinol 1959; 38: 585592.

10. GupTA D, VishwaKarma SK. Toy weapons and firecrackers: a source of hearing loss. Laryngoscope 1989; 99: 330-334.

11. HAMmERNIK RP, AHROON WA, HSUEH KD. Scandinavian Audiology (Noise Induced Hearing Loss) - Literature Review And Experiments If Rabbits. Scandinavian Audiol 1995; 24 (Suppl 40): 132.

12. Robertson D. Combined electrophysiology arifo ultrastructure of acoustic trauma in guinea pig cochleg Arch Otorhinolaryngol 1981; 230: 257-263.

13. Duvall AJ, RoBision KS. Local versus systemge effects of acoustic trauma on cochlear structure as transport. Arch Otolaryngol Head Neck Surg 1980 113: 1066-1071.

14. ZENNER HP. Physiologie und biochemische Grundlagen des normalen und gestörten Gehors. In: Helms J. Oto-Rhino-Laryngologie in Klinik und Praxis. Thieme, Stuttgart: 1995.

15. Lenarz T. Pathophysiologie des Tinnitus. ORL Nova 1995; 5: 142-147.

16. ZENNER HP. Physiologie und biochemische Grundlagen des normalen und gestörten Gehors. In: Helms J. Oto-Rhino-Laryngologie in Klinik und Praxis. Thieme, Stuttgart: 1995.

17. Pilgramm M, SchumanN K. Hyperbaric oxygen therapy for acoustic trauma. Arch Otorhinolaryngol 1985; 214: 247-257. 